\title{
Comparison of Logistics Time of R3A and R3B for Transportation of Lychee Product
}

\author{
Cheosuwan, T. ${ }^{1 *}$ and Udomsripaiboon, T. $^{2}$ \\ ${ }^{1}$ Department of Business Computer, School of Information and Communication Technology, \\ University of Phayao, Phayao Province, Thailand 56000, E-mail: thitirath.ch@up.ac.th \\ ${ }^{2}$ Department of Computer Engineering, School of Information and Communication Technology \\ University of Phayao, Phayao Province, Thailand 56000, E-mail: noah8622@yahoo.com \\ *Corresponding Author \\ DOI: https://doi.org/10.52939/ijg.v17i6.2059
}

\begin{abstract}
This research presents the logistics management information system (LMIS) for the supply chain of lychee products of Phayao Province, Thailand. The main aim of this research is to develop a management application for Phayao's agricultures to improve their competitive abilities on Chinese markets by utilizing a prediction method for traffic congestion based on both real-time and anticipated road traffic. The loss of productivity caused by traffic congestion has become a huge and increasingly heavy burden on Phayao farmers. Therefore, the prediction of urban road network traffic flow and the rapid and accurate evaluation of traffic congestion is of great significance to solve this problem. By using traffic data obtained by distance, road conditions, transportation safety, traffic density, and customs clearance, the local farmers in Phayao can deliver lychee products on time and reduce the loss of high emissions and environmental pollution caused by traffic congestion effectively.
\end{abstract}

\section{Introduction}

China is the largest market for Thailand's agricultural exports from 2012 to 2014. The average income was eight hundred billion baht per year. Phayao, the northern province of Thailand, has many lychee products to export to China such as rice, corn, soybean, green beans, cotton, and ginger. Agricultural shipping from Phayao to China can be delivered by cargo trucks through 2 routes: The R3A Highway and the R3B Highway. The R3A road will be routed through Thailand, Laos, and China and a certain distance along a straight road is 1,300 kilometers. On the other hand, the R3B road, running 1,190 kilometers from Phayao to China via Myanmar, aims to ease travel for tourists wanting to explore foreign cultures and commerce traders seeking new opportunities in neighboring countries. These two roads have the same destination where is the city of Kunming in Yunnan Province, the biggest agricultural product market in southwestern China (Chieh-Yu and Yi-Hui, 2008).

As shown in Figure 1, both the R3A route and the R3B route are jointly developed by four countries: Thailand, Myanmar, Laos, and China. They can be used as the transit route and transport goods between each country. The two routes will converge on the city of Jinghong in China and then go straight to the city of Kunming in the same path and all these routes are also known as the R3 Highway. The importance of the R3 road is a new route that links trade and investment between Thailand, Myanmar, Laos, and China, as well as a strategic route for investment among ASEAN countries. Therefore, the study on the topographical characteristics along the R3 road to developing a software application is a huge challenge. It will be used to guide the economic development of the Phayao province. Additionally, it is important and useful to the direction of Thai economic growth that is interconnected to the ASEAN Community (Yungyu et al., 2005).

With the importance of the R3A and R3B, the authors have studied relevant research to be the guidelines in this project. Some of the literature review and state of art can be described as follows: firstly, Zhiyi gave the intelligent real-time monitoring of logistics information by using the Hadoop cloud computing platform combining with the proposed K-means algorithm to analyze logistics data (Xing, 2021). Secondly, Korth et al., (2018) proposed the system architecture that combines a real-time digital twin of logistics systems. By using this technique, the offline work creating, maintaining and the runtime of the critical real-time uses-case is decreased (Korth et al., 2018). 


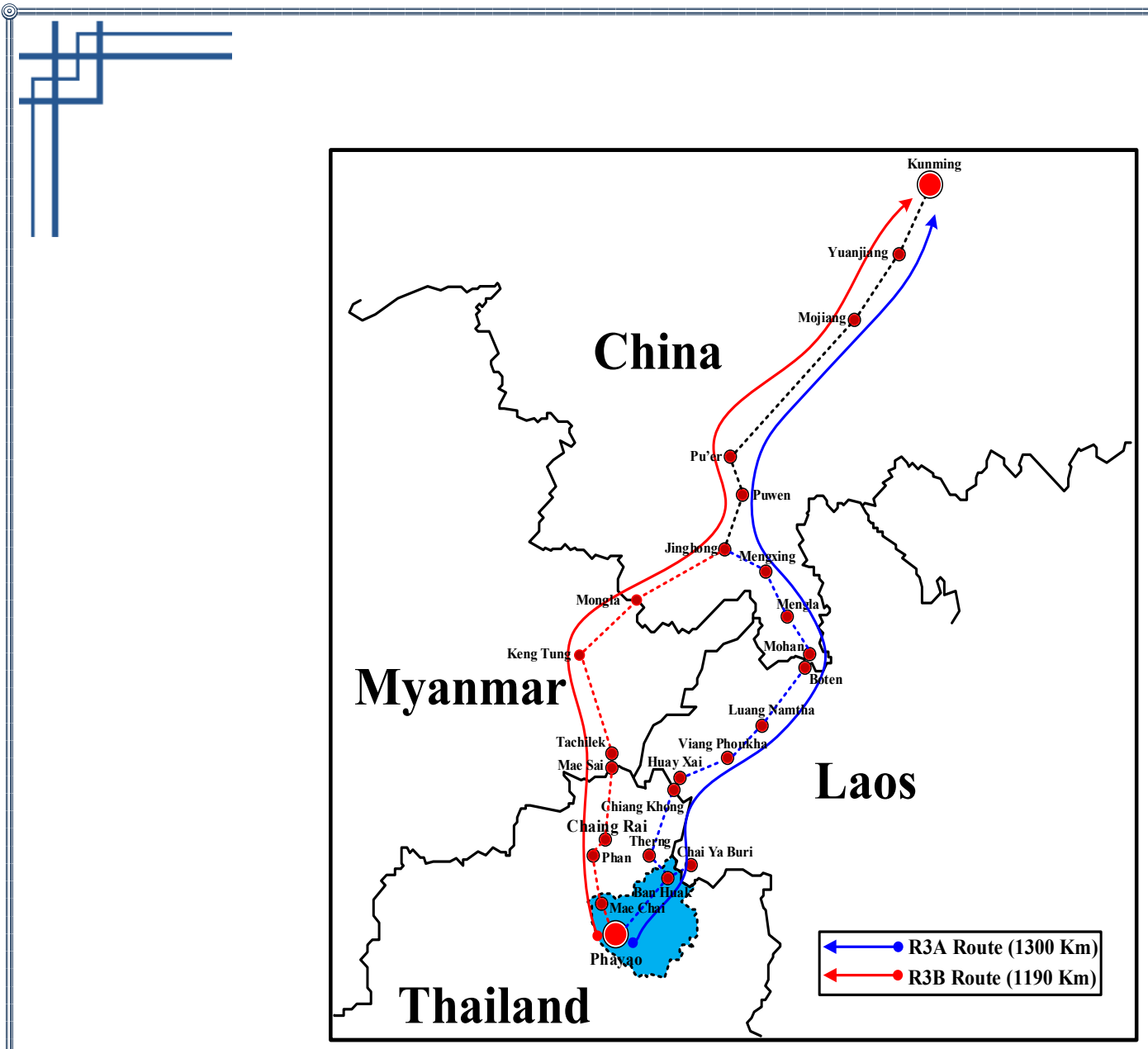

Figure 1: The R3A and R3B highways

Thirdly, the heterogeneous data exchange engine by using the service-oriented framework had been adopted for the improved supply chain information management system. By using this method, the supply-chain data exchange can boost its performance effectively. Simultaneously, the proposed system can reduce the amount of computational (Ben-li, 2018). Finally, Neng et al., (2010) presented the logistics information system with a $\mathrm{B} / \mathrm{S}$ multi-tier architecture. This scheme can be used for decision making in the data search engine accurately. All research studies provide the efficiency of current and future logistics management information system and will be the guidelines for academic researchers in this paper to develop the solutions to the gaps in this project (Linqi and Ershi, 2007, Wu et al., 2009, Weijian et al., 2010, Yanhui 2012, Yun and Liu, 2007 and Zhongwei et al., 2009).

The export of high-quality lychee products in Phayao Province needs effective logistics management that is to decrease cost and improve time efficiency (Becker, 1999). For this reason, this paper presents the logistics management information system (LMIS) for the supply chain to transport on the R3 Highway. It can be used to provide the proper path for transportation route, breakpoints, and available warehouses to the cargo trucks on the R3 road. The proposed system is relied on real-time information to help the decision support system such as internal logistics system, inbound logistics system, and outbound logistics system. The system will also provide the best route for transportation to an agribusiness operator to choose the most appropriate path to the city of Khun Ming. Thus, by this proposed system, the agricultural operators or farmers can minimize costs and transport to China in the most efficient way possible.

\section{Objectives}

To propose the LMIS for the supply chain of lychee products of Phayao Province, the northern region in Thailand. This is an evaluation of the logistics management information system used in Thailand, Myanmar, Laos, and China in the years 2018-2020.

\section{Research Hypothesis}

The proposed system directly impacts agricultural operators, farmers, and economic growth in Phayao Province. Moreover, in the indirect impact, the 
proposed system can reduce the traffic flow on the $\mathrm{R} 3$ route resulting in the reduction of carbon monoxide emissions. This makes global more environmentally friendly.

\section{Research Methodology}

This research deploys various parameters to create the prediction of traffic congestion between the R3A route and the R3B route such as the traffic volume, the rate of flow, the occurrence of queues, the peak hour factor, the speed and travel time, the time-mean speed, and space mean speed. They all can be explained as follows.

\subsection{Traffic Volume and Rate of Flow}

According to Roess et al., (2010), the traffic volume is the number of agricultural trucks moving through an observed point on the road (a breakpoint or a warehouse) in a defined period, and it is in vehicles per time unit (usually an hour). In addition, the rate of flow is the number of agricultural trucks that pass an observed point through a time interval of less than an hour (usually 15 minutes).

\subsection{The Occurrence of Queues on the Road}

The occurrence of queues can be analyzed from the traffic volume and rate of flow and can be found how to calculate this value from (Roses et al., 2010).

\subsection{The Peak Hour Factor (PHF)}

The peak hour factor is the hourly traffic volume during the maximum-volume hour of the day divided by the busiest 15-minute flow rate within the peak hour. It is used to define how consistent traffic volume is during the peak hour. The PHF can be calculated following Equation (1):

$$
\text { PHF }=\frac{\text { Hourly Volume }}{\text { Maximum Rate of Flow }},
$$

Eqaution 1

and the standard 15-minute analysis period can be expressed as follows:

$$
\text { PHF }=\frac{\text { HourlyVolume }}{4 \times V_{m 15}},
$$

Equation 2

which $V_{m 15}$ is maximum 15-minute volume within an hour.

\subsection{The Speed and Travel Time}

The speed and travel time is the movement rate in the time-per-time unit or the inverse of time used by agricultural trucks to move in a given distance multiplied by distance. It is calculated as follows:

$$
s=\frac{d}{T},
$$

Equation 3

where $S$ is speed, $d$ is distance traversed, and $T$ is time to traverse distance.

\subsection{Time Mean Speed and Space Mean Speed}

The average speed of an agricultural truck can be calculated in two ways: Time Mean Speed (TMS) and Space Mean Speed (SMS). First, TMS is the average speed of all agricultural trucks that run past any location on the R3A road for a specified period. Second, SMS is the average speed of all agricultural trucks that occupy road ranges that are considered for a specified period. Both of them can be shown as:

$$
T M S=\frac{\sum_{i}\left(\frac{d}{t_{i}}\right)}{n},
$$

and

Eqaution 4

$$
S M S=\frac{d}{\left(\frac{\sum_{i} t_{i}}{n}\right)}=\frac{n d}{\sum_{i} t_{i}},
$$

Equation 5

where $n$ is the amount of travel time data that can be observed, and $t_{i}$ the time to traverse distance of $i^{\text {th }}$ agricultural trucks.

\subsection{The Analysis of Performance Evaluation Results}

We are carried out by measuring satisfaction from the use of the system from the users two times: before using (pre) and after using (post) the system. The performance evaluation results are based on both the arithmetic averages and the standard deviation method. They all can be expressed as follows:

$$
\bar{X}=\frac{\sum f x}{k},
$$

Eqaution 6

and

$$
S=\sqrt{\frac{n \sum f x^{2}-\left(\sum f x\right)^{2}}{k(k-1)}},
$$

where $\bar{X}$ is the arithmetic averages, Equation 7 $\sum f x$ is the sum of the estimated values, $k$ is the number of samples, and $S$ is the standard deviation. 


\section{Results and Discussion}

This research is used data by interviewing and questioning the sample group of both farmers and logistics operators in Phayao province. Moreover, we study the shipping process, the supply chain management, and logistics of lychee products respectively (Burrough and McDonnell ,1998, Guerlain et al., 2016, Cowen and Shirley, 1991, McFarlane et al., 2016, Russell, 2009 and Stock and Lambert, 2007). As a result, all information from this study is deployed to design the proposed application. The process flow of lychee products from Thailand to China can be shown in Figure 2 and Figure 3 respectively.

\subsection{The System Analysis and Design}

According to field data collection and the comparative data analysis of $\mathrm{R} 3 \mathrm{~A}$ and $\mathrm{R} 3 \mathrm{~B}$ routing travel such as the traffic volume, the rate of flow, the occurrence of queues, the peak hour factor, the speed and travel time, the time-mean speed, and space mean speed, both of them can be shown in Tables 1, 2 and 3 respectively.

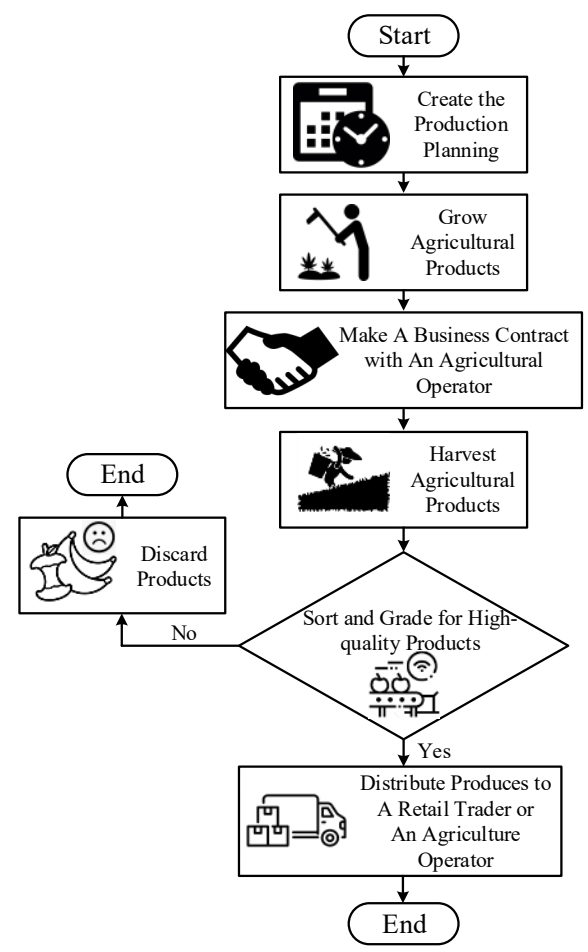

Figure 2: The process flow of agricultural products: the farmers' operation workflow

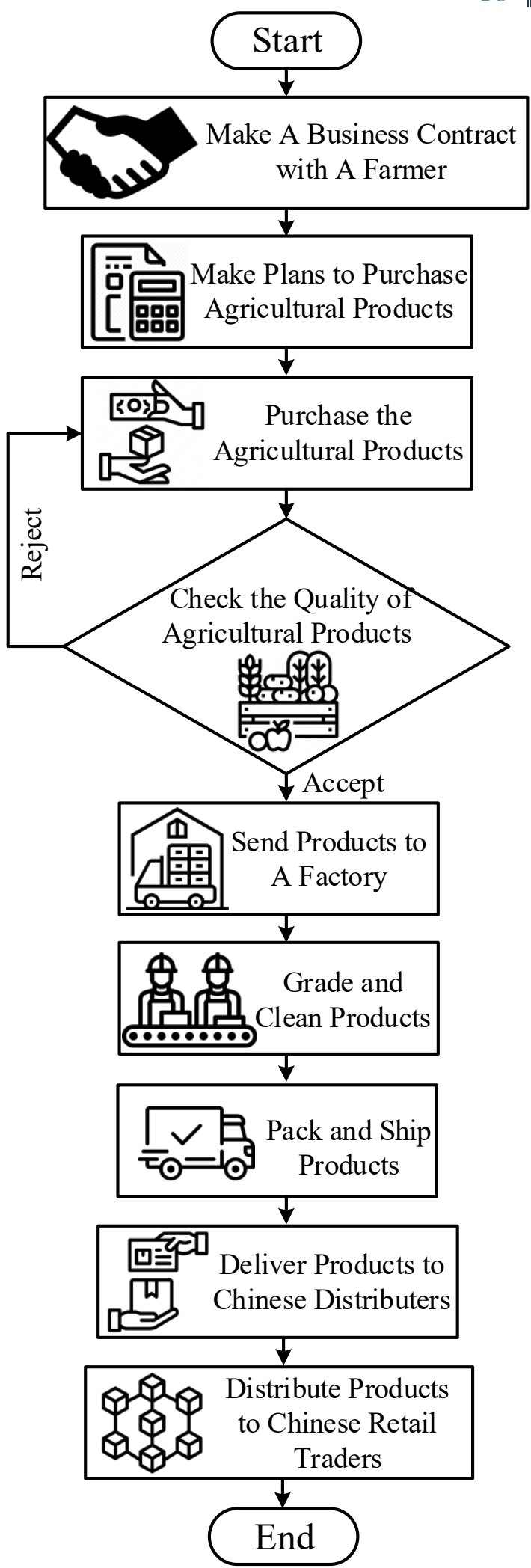

Figure 3: The process flow of agricultural products: the operators' operation workflow 
Table 1: The calculation of the peak hour factor on both R3A and R3B routes

\begin{tabular}{|c|c|c|c|c|c|c|c|c|c|c|c|c|}
\hline \multirow{3}{*}{\begin{tabular}{|r} 
Time \\
Morning
\end{tabular}} & \multicolumn{6}{|c|}{ Traffic volume } & \multicolumn{6}{|c|}{ Rate of flow } \\
\hline & \multicolumn{2}{|c|}{ Thai truck } & \multicolumn{2}{|c|}{ Foreign truck } & \multicolumn{2}{|c|}{ Total } & \multicolumn{2}{|c|}{ Thai truck } & \multicolumn{2}{|c|}{ Foreign truck } & \multicolumn{2}{|c|}{ Total } \\
\hline & R3A & R3B & R3A & R3B & R3A & R3B & R3A & R3B & R3A & R3B & R3A & R3B \\
\hline $\begin{array}{l}\text { 07:00-07:15 } \\
\text { AM }\end{array}$ & 24 & 12 & 6 & 15 & 30 & 27 & 96 & 48 & 24 & 60 & 120 & 108 \\
\hline $\begin{array}{l}07: 16-07: 30 \\
\text { AM }\end{array}$ & 18 & 8 & 4 & 10 & 22 & 18 & 72 & 32 & 16 & 40 & 88 & 72 \\
\hline $\begin{array}{l}07: 31-07: 45 \\
\text { AM }\end{array}$ & 20 & 11 & 5 & 8 & 25 & 19 & 80 & 44 & 20 & 32 & 100 & 76 \\
\hline $\begin{array}{l}\text { 07:46-08:00 } \\
\text { AM }\end{array}$ & 16 & 8 & 8 & 15 & 24 & 23 & 64 & 32 & 32 & 60 & 96 & 92 \\
\hline Total & 78 & 39 & 23 & 48 & 101 & 87 & 312 & 156 & 92 & 192 & 404 & 348 \\
\hline \multicolumn{5}{|c|}{ Traffic volume range 07:00-08:00 AM } & 101 & 87 & \multicolumn{6}{|c|}{$\begin{array}{l}\text { R3A: } 101 \mathrm{vph}=\text { Hourly volume } \\
\text { R3B: } 87 \mathrm{vph}=\text { Hourly volume }\end{array}$} \\
\hline \begin{tabular}{|l|} 
Afternoon \\
\end{tabular} & R3A & R3B & R3A & R3B & R3A & R3B & R3A & R3B & R3A & R3B & R3A & R3B \\
\hline $\begin{array}{l}\text { 01:00-01:15 } \\
\text { PM }\end{array}$ & 10 & 7 & 8 & 14 & 18 & 21 & 40 & 28 & 32 & 56 & 72 & 84 \\
\hline $\begin{array}{l}01: 16-01: 30 \\
\text { PM }\end{array}$ & 7 & 9 & 5 & 6 & 12 & 15 & 28 & 36 & 20 & 24 & 48 & 60 \\
\hline $\begin{array}{l}\text { 01:31-01:45 } \\
\text { PM }\end{array}$ & 12 & 12 & 6 & 9 & 18 & 21 & 48 & 48 & 24 & 36 & 72 & 84 \\
\hline $\begin{array}{l}\text { 01:46-02:00 } \\
\text { PM }\end{array}$ & 9 & 14 & 4 & 8 & 13 & 22 & 36 & 56 & 16 & 32 & 52 & 88 \\
\hline Total & 38 & 42 & 23 & 37 & 61 & 79 & 152 & 168 & 92 & 148 & 244 & 316 \\
\hline \multicolumn{5}{|c|}{ Traffic volume range 01:00-02:00 AM } & 61 & 79 & \multicolumn{6}{|c|}{$\begin{array}{l}\text { R3A: } 61 \mathrm{vph}=\text { Hourly volume } \\
\text { R3B: } 79 \mathrm{vph}=\text { Hourly volume }\end{array}$} \\
\hline \begin{tabular}{|l|} 
Evening \\
\end{tabular} & R3A & R3B & R3A & R3B & R3A & R3B & R3A & R3B & R3A & R3B & R3A & R3B \\
\hline $\begin{array}{l}\text { 04:00-04:15 } \\
\text { PM }\end{array}$ & 6 & 4 & 4 & 5 & 10 & 9 & 24 & 16 & 16 & 20 & 40 & 36 \\
\hline $\begin{array}{l}\text { 04:16-04:30 } \\
\text { PM }\end{array}$ & 5 & 5 & 7 & 6 & 12 & 11 & 20 & 20 & 28 & 24 & 48 & 44 \\
\hline $\begin{array}{l}\text { 04:31-04:45 } \\
\text { PM }\end{array}$ & 7 & 2 & 5 & 4 & 12 & 6 & 28 & 8 & 20 & 16 & 48 & 24 \\
\hline $\begin{array}{l}\text { 04:46-05:00 } \\
\text { PM }\end{array}$ & 11 & 3 & 8 & 3 & 19 & 6 & 44 & 12 & 32 & 12 & 76 & 24 \\
\hline Total & 29 & 14 & 24 & 18 & 53 & 32 & 116 & 56 & 96 & 72 & 212 & 128 \\
\hline \multicolumn{5}{|c|}{ Traffic volume range 04:00-05:00 AM } & 53 & 32 & \multicolumn{6}{|c|}{$\begin{array}{l}\text { R3A: } 53 \mathrm{vph}=\text { Hourly volume } \\
\text { R3B: } 32 \mathrm{vph}=\text { Hourly volume }\end{array}$} \\
\hline \multicolumn{5}{|c|}{ Traffic volume average (Trucks) } & 71.66 & 66 & \multicolumn{6}{|c|}{$\begin{array}{l}\text { R3A: } 71.66 \mathrm{vph}=\text { Hourly volume } \\
\text { R3B: } 66 \mathrm{vph}=\text { Hourly volume }\end{array}$} \\
\hline
\end{tabular}

Table 2: The calculations of both the peak hour factor and the hourly traffic volume during the maximumvolume hour of the day divided by the busiest 15 -minute $(\mathrm{veh} / \mathrm{h})$

\begin{tabular}{|c|c|c|c|}
\hline Time period & $\begin{array}{c}\text { Hourly volume } \\
\text { (Truck : Hour) }\end{array}$ & PHF & $\begin{array}{c}\text { Maximum traffic volume } \\
\text { (15 minute sub-period) }\end{array}$ \\
\hline R3A-Morning & 101 & 0.84 & 120 \\
\hline R3A-Afternoon & 61 & 0.85 & 72 \\
\hline R3A-Evening & 53 & 0.70 & 108 \\
\hline R3B-Morning & 87 & 0.81 & 88 \\
\hline R3B-Afternoon & 79 & 0.90 & 36 \\
\hline R3B-Evening & 32 & 0.89 & \\
\hline
\end{tabular}

\subsection{The Use Case Diagram}

The use case diagram represents capabilities or functions that the proposed application can perform. All use cases can be shown as nine modules: R3A Transportation Map Management, R3B Transportation Map Management, Traffic Monitor and Trucks Management, Transportation Routes Management, Transportation Tracking Management,
Traffic Density Model Management, Weather Forecasting Link Management, Emergency Call Management, and Notifications / Problem Notifications Management (Whitten and Bentley, 2007 and Sanjaya and Perdana, 2015). The use case diagram of the proposed system can be shown in Figure 4. 


\begin{tabular}{l} 
Table 3: The queuing analysis \\
Time \\
\cline { 2 - 9 }
\end{tabular}

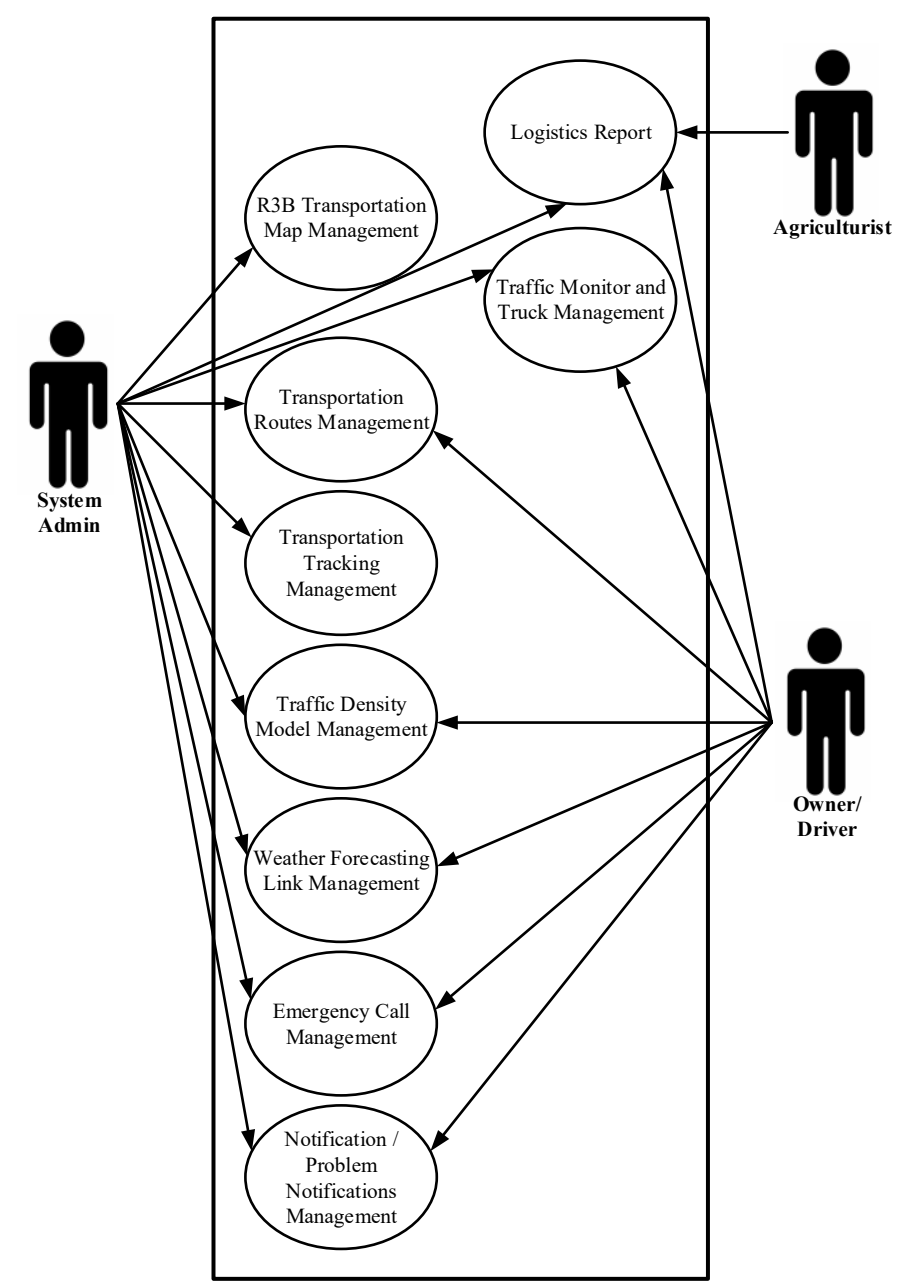

Figure 4: The use case diagram of the proposed system 

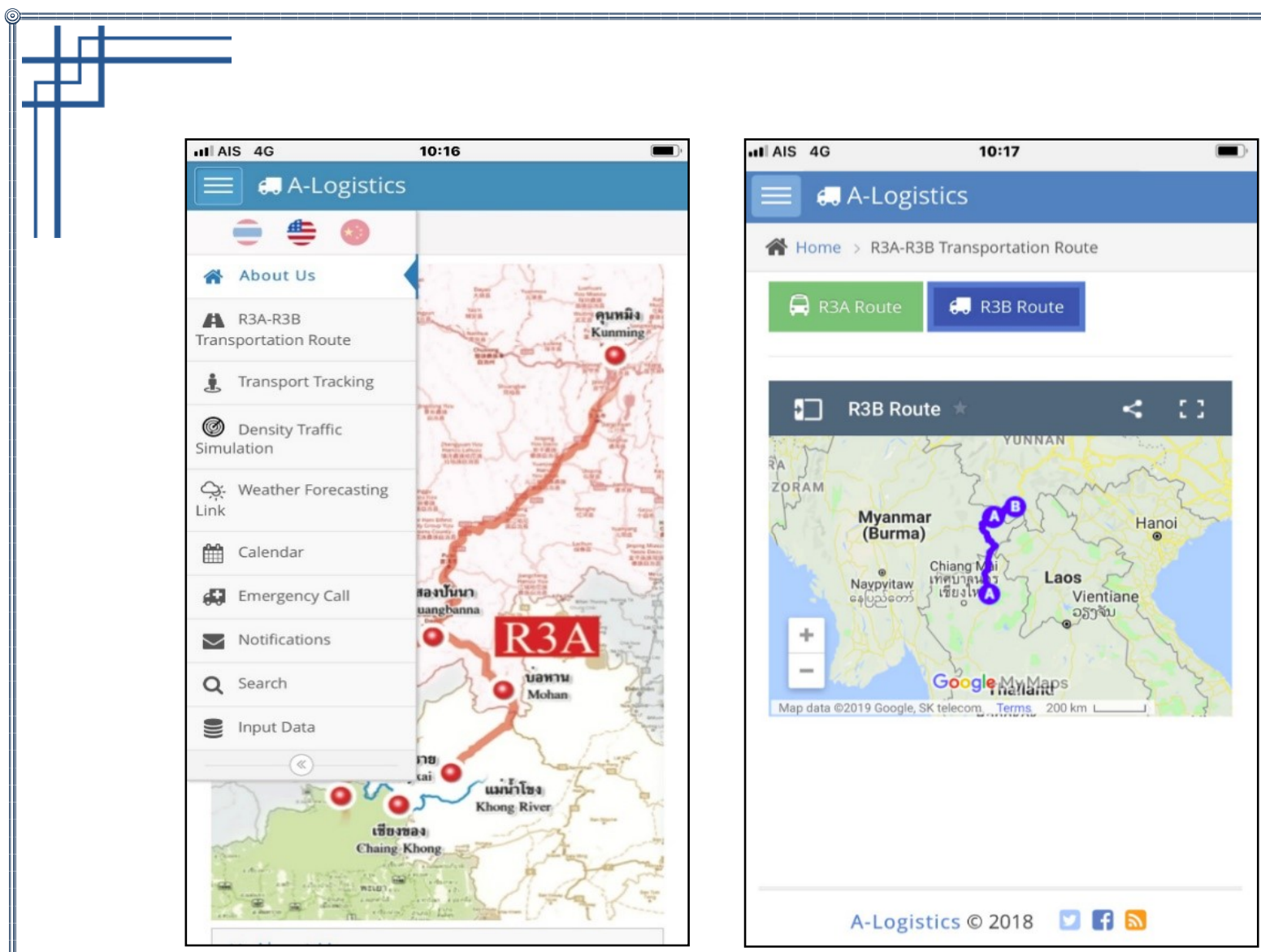

(a) The overall main page

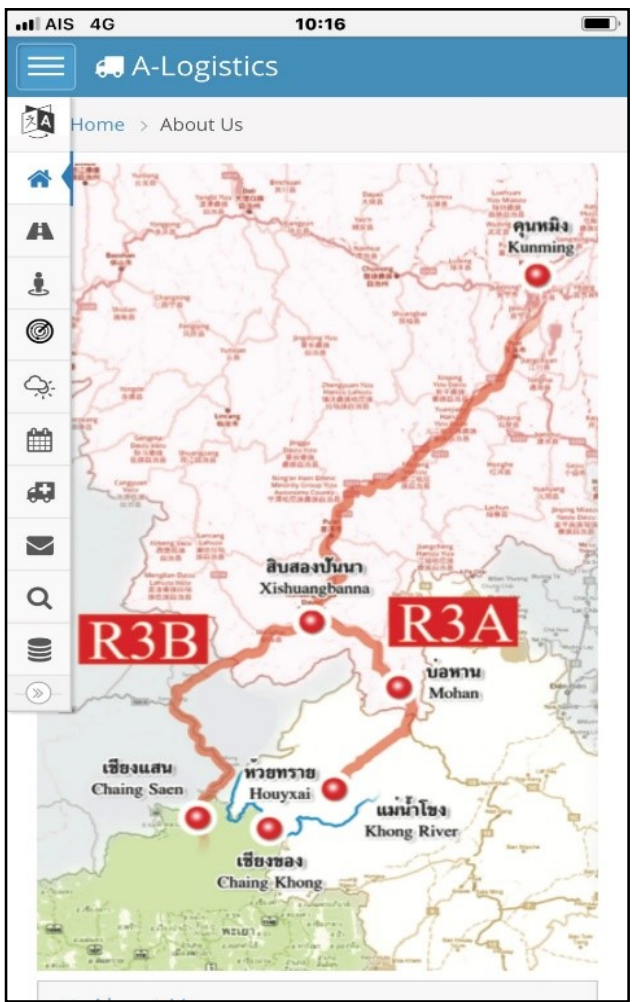

c) The transport tracking

(b) The transport decision-making map

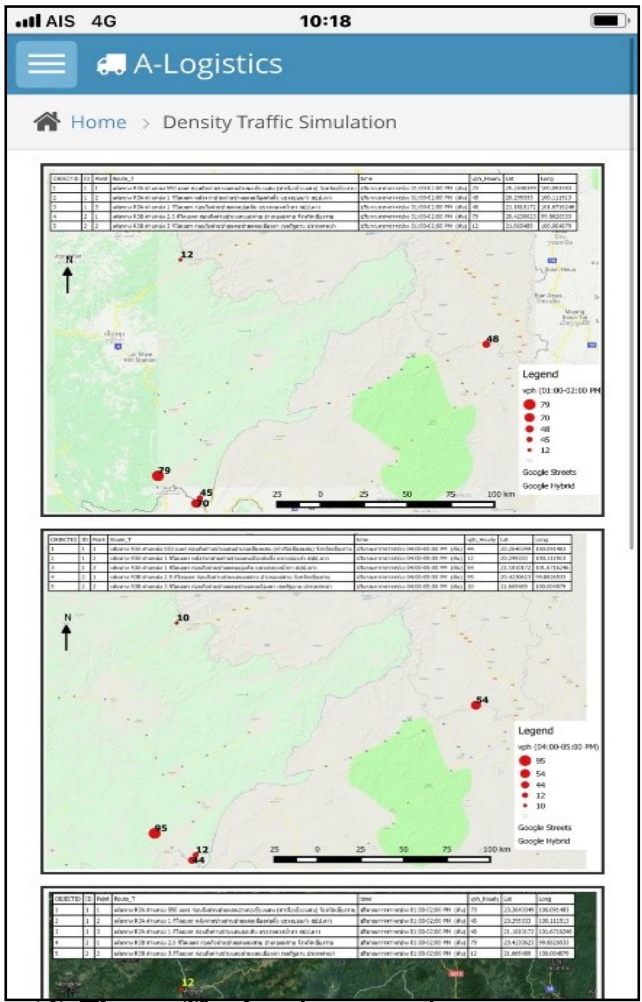

(d) The traffic density reporting

Figure 5: The mobile application of the proposed system

International Journal of Geoinformatics, Vol. 17, No. 6, December 2021 


\subsection{The System Design}

According to Neng et al., (2010) the overall architecture of the proposed system can be shown in Figure 6. The system admin, truck drivers, and farmers can access real-time information with existing data. The system provides the initial username and password for all users according to the permissions for different personalities. Moreover, the system admin can access all areas of the user information and can set each permission level. Thus, each user can only use the business within their permissible limits.

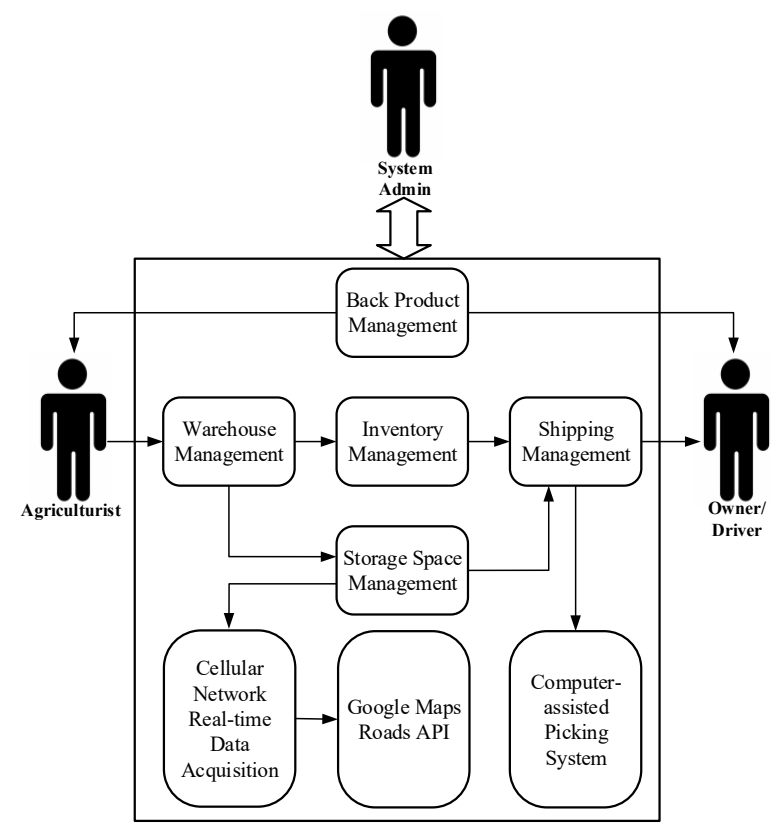

Figure 6: The overall architecture of the logistics information system

The proposed application is based on web browsers, which can be assessed by many types of smart devices such as smartphones, tablets, and personal computers respectively. The application has been designed with functionality in line with three groups of users: system admins, truck drivers, and farmers respectively. All functionalities of the application for mobile devices can be shown in Figure 5. The logistics management information system for the supply chain of lychee products in Phayao province can be founded and used on https://thdw.ict.up.ac.th/alo/Simulate.aspx for related users.

\subsection{Analyzing and Reporting Assessment Results}

The proposed system is evaluated by five functionalities: functional requirement, system design, performance, reliability, and usability. The assessment of the evaluation is carried out by Best's
Law (Best, 1981). The score can be divided into five ranges: 1.00 to 1.49 for the below average, 1.50 to 2.49 for average, 2.50 to 3.49 for above average, 3.50 to 4.49 for good, 4.50 to 5.00 for very good. The total number of the sample is 145 people: logistic operators for 25 people and farmers for 120 people (46 males and 99 females).

For assessment of the functional requirement, Figure 7 shows that the farmers are highly satisfied with the System Control, but not satisfied with the Input Data.

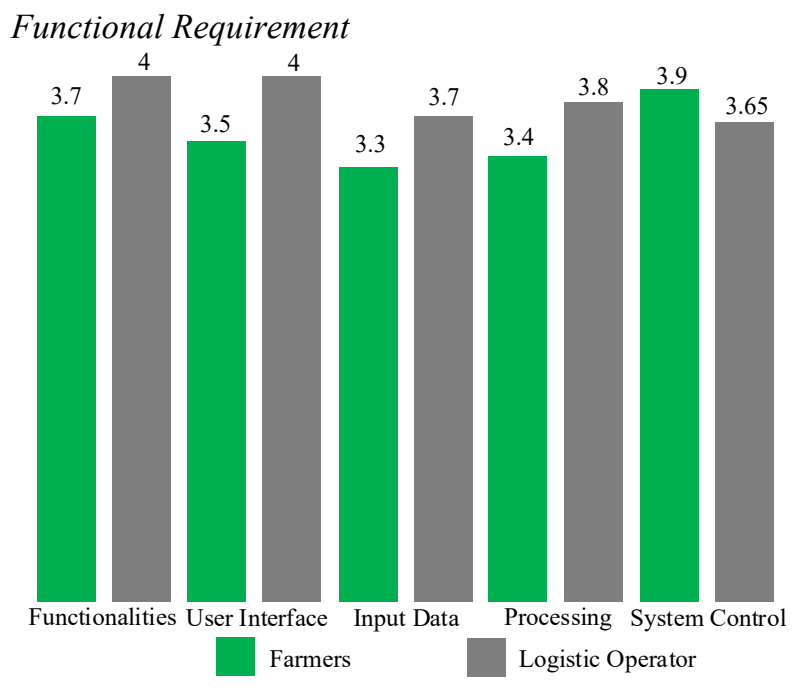

Figure 7: The assessment of the functional requirement

On the other hand, the logistic operators are most satisfied with both the Functionalities and the User Interface, but can't be satisfied at the System Control. The assessment of the system design can be shown in Figure 8.

\section{System Design}

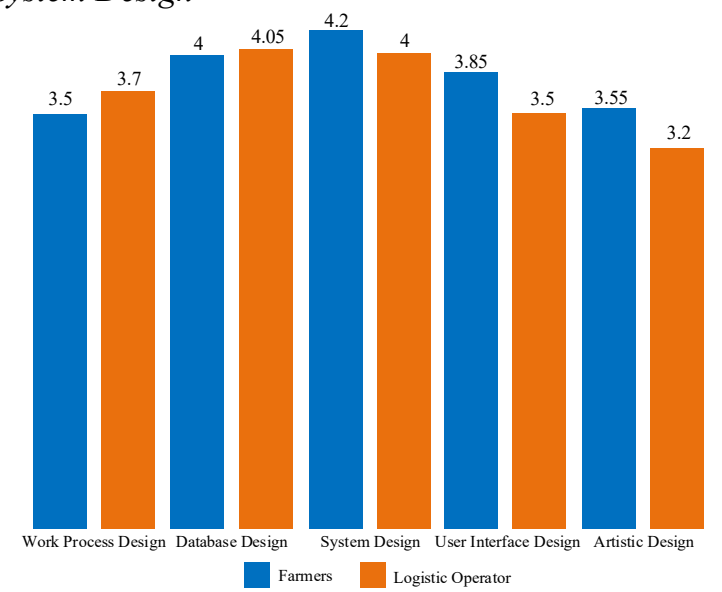

Figure 8: The assessment of the system design 
All farmers are very satisfied with the System Design, but are the least satisfied with the Work Process Design. In contrast, the logistic operators have a high level of satisfaction with the Database Design, but a low level of satisfaction with the Artistic Design respectively. Figure 9 shows the assessment of the performance. The assessment score of the Processing Accuracy is the highest, but the Reliability is the lowest for the farmers. On the contrary, for the logistic operators, the highest score of the assessment is the Comfortable to Use, but the lowest score of the assessment is the System Workflow.

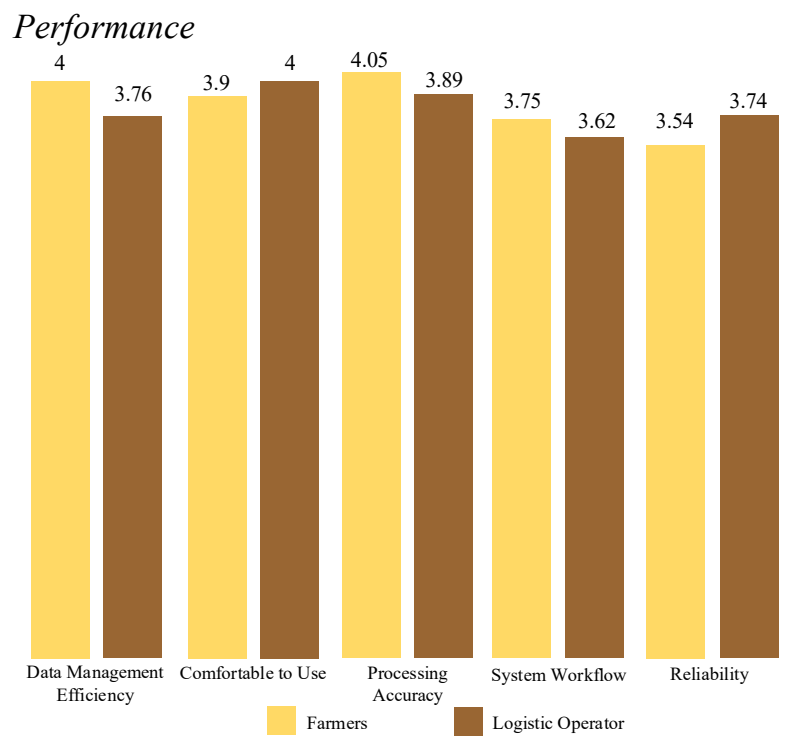

Figure 9: The assessment of the performance

\section{Reliability}

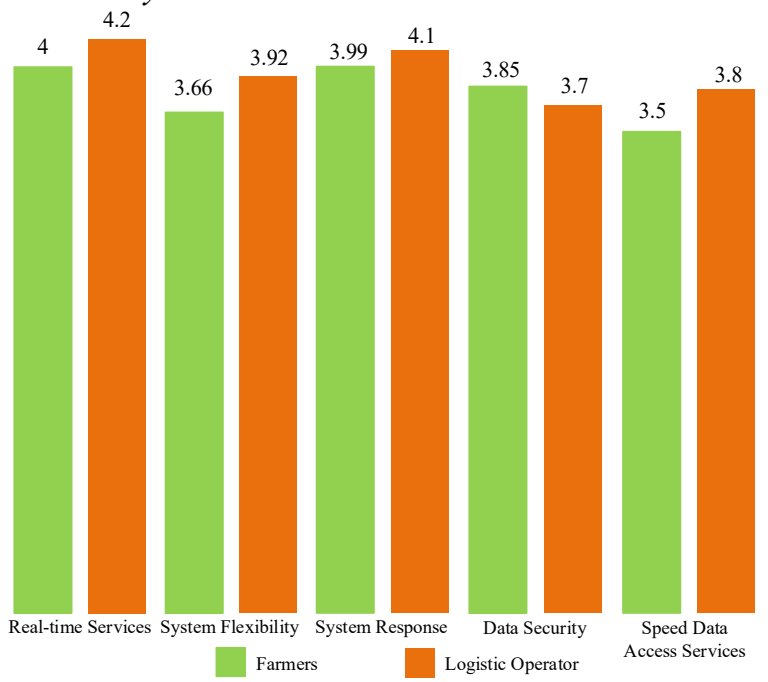

Figure 10: The assessment of reliability
Figure 10 illustrates the assessment of reliability. The Real-time Services can offer the most impressive for both farmers and logistic operators, while the Speed Data Access Service and the Data Security provide the lowest impressive for farmers and logistic operators respectively. The assessment of usability can be shown in Figure 11. Farmers give the highest score of the assessment for the Transportation Decision Support, and the lowest score for the Report Accuracy. Conversely, the logistic operators have a maximum score of the assessment with the Logistic Management Support, but a minimum score with the Security Protection. From the summary of the system evaluation scores by farmers and logistics operators, it is found that they are most likely satisfied with the proposed system by rating the system in the range between 3.20 to 4.20 , which is a level above the average of about 2.5 in all sides of the functionalities. It shows that whether farmers or logistics operators are impressed by the overall installed system because it facilitates transportation and logistics from Phayao to Khun Ming. The authors of this research hope that the system will be able to develop on other important routes. As a result, this will benefit farmers and logistic operators in Thailand to transport lychee products with Phayao Province as a distribution point to various countries. The assessment results can be shown as follows.

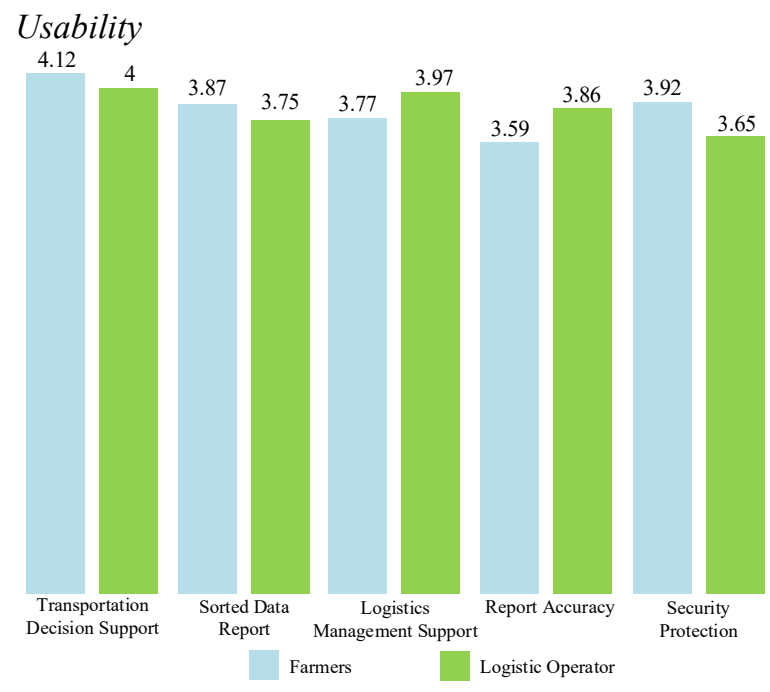

Figure 11: The assessment of usability

\section{Conclusion}

The logistics management information system (LMIS) is presented in this paper. It facilitates the supply chain of lychee products of Phayao Province, Thailand. The major goal of this paper is to provide a management application for the farmers and 
logistic operators in Phayao Province to compete in China's agricultural industry. The proposed system will provide a prediction of the real-time traffic congestion by using traffic data obtained by information from the Google Road Maps APIs on both $\mathrm{R} 3 \mathrm{~A}$ and $\mathrm{R} 3 \mathrm{~B}$ routes such as distance, road conditions, and traffic density. Anyway, some information needs to request from truck drivers by chatting on the proposed mobile application to a system administrator such as transportation safety and customs clearance. Therefore, this technique reduces the rots and spoilage of lychee products and increases income for both farmers and logistic operators.

Moreover, the indirect advantage is that it can reduce business gas usage, resulting in lower air pollution from traffic congestion. As a result, from the proposed LMIS, both farmers and logistic operators are satisfied with the offered system, with the evaluated results over the average score of the assessment in all sides of the functionalities.

\section{Acknowledgement}

First and foremost, we would like to express our deepest gratitude to the University of Phayao for its supports both the research fund and many facilities. Also, we would like to express our sincere thanks to all workers who work in the School of Information and Communication Technology, the University of Phayao for their supports and encouragement throughout this research. Last, but not least, our thanks go to all readers who are reading this paper and we accept all comments and recommendations arising from this article.

\section{References}

Becker T., 1999, The Economic of Food Quality Standards. The $2^{\text {nd }}$ Interdisciplinary Workshop on Standardization Research, University of the Federal Armed Force Hamburg, Hamburg, German.

Ben-li Z., 2018, Service-oriented Logistics Supply Chain Information Management System, The International Conference on Intelligent Transportation, Big Data \& Smart City, Xiamen, China.

Best, W. J., 1981, Research in education (4th ed.), New Jersey: Prentice Hall.

Burrough, P. A. and McDonnell, R. A., 1998, Principle of Geographical Information Systems, New York: Oxford University Press.

Chieh-Yu, L. and Yi-Hui, H., 2008, Technological Innovation for China' $\mathrm{s}$ Logistics Industry.
Journal of Technology Management \& Innovation, Vol. 2(4), 1-19.

Cowen, D. J. and Shirley, W. L., 1991, Integrated Planning Information Systems, Geographic Information Systems, [Available online at http://citeseerx.ist.psu.edu.].

Guerlain, C., Cortina S. and Renault, S., 2016, Towards a Collaborative Geographical Information System to Support Collective Decision Making For Urban Logistics Initiative. Transportation Research Procedia, Vol. 12, 634-643, https://doi.org/10.1016/j.trpro.2016.02.017

Korth, B., Schwede, C. and Zajac, M., 2018, Simulation-Ready Digital Twin for Real Time Management of Logistics Systems. Proceeding of the IEEE International Conference on Big Data, Seattle, WA, USA. DOI:10.1109/BigData.2018 .8622160 .

Linqi, G. and Ershi, Q., 2007, Study on Cooperative Logistics Information System According to Supply Chain Management, Proceeding of IEEE International Conference on Automation and Logistics, Jinan, China. DOI: 10.1109/ICAL.2007.4339014.

McFarlane, D., Giannikas, V., and Lu, W., 2016, Intelligent Logistics: Involving the customer, Computers in Industry, DOI:10.1016/j.compind.2015.10.002.

Neng, W. and Fenghua, X., 2010, Design of Logistics Information Management System Based on Database, The $2^{\text {nd }}$ International Conference on Computer Modeling and Simulation, Sanya, China. DOI: 10.1109/ICCMS.2010.343.

Roses, R. P., Prassas, E. S. and McShane, W. R., 2010, Traffic Engineering (4th ed.), Pearson Press.

Russell, S., 2009, Supply Chain Management: More Than Integrated Logistics. Air Force Journal of Logistics, Vol. 2,55-63.

Sanjaya, S. and Perdana, T., 2015, Logistics System Model Development on Supply Chain Management of Tomato Commodities for Structured Market, Procedia Manufacturing, Vol. 4, 513-520.

Stock, J. R. and Lambert, D. M., 2007, Strategic Logistics Management, World Bank.

Weijian, H., Hua, Z., Liang, H., and Wei, D., 2010, Management Information System Applied in the Logistics, Proceeding of International Conference on Intelligent Computation Technology and Automation, Changsha, China. 

Analysis and Design Methods (7 ${ }^{\text {th }}$ ed.), New York: McGraw Hill.

Wu W., Huang Y., and Wu J., 2009, The Design Based on the Logistics Foodstuffs Management Information System, Proceeding of International Forum on Information Technology and Applications, Chengdu, China.

Xing, Z., 2021, Research on Logistics Management Information System Based on Big Data, Proceeding of the International Conference on Measuring Technology and Mechatronics Automation (ICMTMA), Beihai, China.

Yanhui, J., 2012, Research on the Construction of Logistics Finance Information System, Proceeding of International Conference on Management of e-Commerce and e-Government, Beijing, China.

Yun,, Q. and Liu, B., 2007, Returns Management Information System: A Case of Paint Manufacturers, Proceeding of International Conference on Service Systems and Service Management, Chengdu, China.

Yung-yu, T.,Yue, W. L., and Taylor, M., 2005, The Role of Transportation in Logistics Chain, Proceeding of the Eastern Asia for Transportation, Vol. 5, 1657-1672.

Zhongwei, W., Hongbo, W., and Yan, P., 2009, Integration of Logistics Information System and RFID Technology: A Case Study of Jinxia Logistics Park, Proceeding of International Conference on Information Technology and Computer Science, Vol.2: 138-141. 